\title{
DATE DUE FOR
}

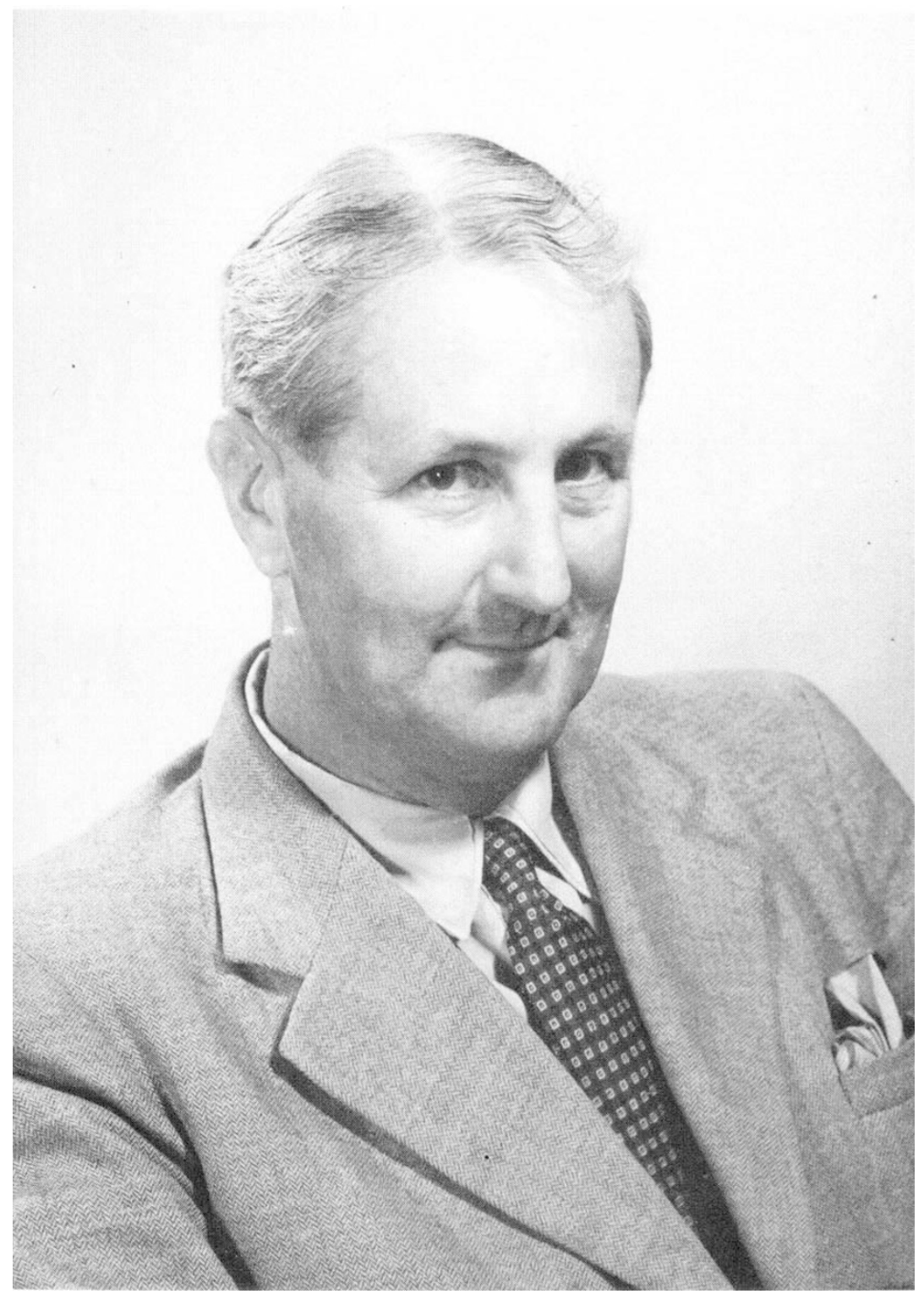

Cyril Dean Darlington 
(C) 1982. The Genetical Society of Great Britain

\section{CYRIL DEAN DARLINGTON}

1903-1981

IN the year 1923 Cyril Dean Darlington started unpaid work at the John Innes Horticultural Institution at Merton, London under William Bateson, to "assist the regular staff and to make use of the facilities provided"; 58 years later, still devoted to the study of chromosomes, the gene, evolution and man, his work and life came to an end. At the end, on 26 March 1981 he was completely absorbed in writing a book which was to carry to the limit the notions of determinants, introduced as he has said by Weismann, in the cell, individual and population especially when acted upon by natural selection and undergoing evolution. Only months before at a Royal Society Symposium on manipulation of genetic systems in plant breeding he gave the invited introduction in a brilliant, imaginative, penetrating and elegant style with his characteristically controlled enthusiasm and scepticism, the memory of which encourages the thought that the half-written book might have matched the early masterpieces "Recent Advances in Cytology" and "The Evolution of Genetic Systems".

Darlington was born on 19 December 1903 at Chorley, Lancashire, England, the son of William Henry Robertson Darlington and Ellen née Frankland, educated at Boteler Grammar School, Warrington, Mercer's School, Holborn and St. Paul's School, London. In 1923 he graduated B.Sc. in agriculture from Wye College, University of London with the view to farming in Australia. Fortunately for science a turning point came before he migrated to Australia when he read "The Physical Basis of Heredity" by Morgan, Sturtevant and Bridges. This book alone fired his imagination and set the course of his life's work, so that instead of farming he persuaded Bateson to accept him as a volunteer worker at the John Innes Horticultural Institution. Bateson, after his visit in 1922 to Morgan's laboratory at Columbia U.S.A., was at last converted to the chromosome theory of heredity and had appointed W. C. F. Newton, "a trained cytologist" to the staff in 1922 but whose career was to be cut short by an untimely death. Darlington was encouraged to work on three types of problems, each with their different plant materials. (1) Studies on the structure, mechanics and division of the chromosomes particularly at meiosis using Liliaceous plants with large chromosomes, this was at first done in close collaboration with Newton; (2) studies on plants with a known genetic background such as Primula sinensis and Prunus spp., but with chromosomes that were small and less favourable for study; and (3) the study of variegation by breeding not by cytology, particularly in Vicia faba. Darlington's first choice was the study of meiosis in large chromosomes, the study of the less amenable material of Prunus and Primula was very much a second choice, augmented by the availability of these plants and their known genetics. The study of variegation was to him a chore and an example of "assisting the regular staff" and in fact the Director, Bateson. But all of these diverse studies in their own way came to fruition. A series of papers on meiosis, chiasmata and crossing over and chromosome pairing 
in diploids and polyploids arising from the study of large chromosomes, and synthesised into his book "Recent Advances in Cytology", made an impact that was immediate and world wide. At the fifth International Genetics Congress (1932) the leading cytologists Belling, Stern, Federley and Huskins devoted substantial parts of their addresses to try, unsuccessfully, to disprove Darlington's theories. Since then the book has been described as converting the chaos of the cell into the science of cytology and has for many, who have since become distinguished, been a source of inspiration and possibly a turning point in their own careers. Darlington's debt to Morgan, Sturtevant and Bridges was fully repaid within 9 years at the age of 29 by his own masterpiece.

The study of Primula and Prunus with its connotations beyond the structure and mechanisms of the chromosomes by its concern with polyploidy, hybridity, breeding systems and genes may have been the start of his concern with evolution and genetic systems, an interest which started less explosively than the pure chromosome studies but one which persisted as a main source of inspiration and thought throughout his life. The study of variegation in Vicia faba, summarised in a paper in the Journal of Genetics appeared to have no immediate impact either on Darlington or others, for irregularities which were inexplicable on Mendelian lines were not fit subjects for study by the conventional geneticist. It may be, however, that this early work lay dormant in his mind and came forth later in his great theoretical contribution to cytoplasmic inheritance, plasmagenes and viruses, and to the later interest in variegated plants as evidenced by the collection in the Genetic Garden which he formed at Oxford and the definitive book on variegation by one of his former students.

To appreciate Darlington's immense contribution to the advancement of our knowledge of the chromosomes we must bear in mind the contemporary ignorance of their structure and the disagreement about the meaning of several major features of their reproduction and division. Were the chromosomes seen at meiosis double structures because they were paired chromosomes or because they were single chromosomes that had replicated but not separated? This was settled by Newton from a study of chromosomes in Galtonia, one year before Darlington came to work with him, and it is tempting to think this focussing of attention on the nature of single and double structures seen at mitosis and meiosis might have been the trigger for Darlington's highly ingenious and beautifully simple precocity theory of meiosis in which the nucleus begins prophase before the chromosomes have divided, in contrast to mitosis where the first visible chromosomes are double. The theory has not yet been disproved and has recently been supported at the molecular level, for although the bulk of DNA and chromosomal protein synthesis is during the resting stage in both mitosis and meiosis, Dr J. S. Parker has pointed out to me that some significant semi-conservative DNA synthesis, which is not repair synthesis, occurs at zygotene, late in the meiotic division.

Was the pairing of the chromosomes at meiosis a lateral or terminal process-parasynapsis or telosynapsis? This basic problem was confused by inadequate observations, unsuitable material for studying the crucial pachytene stage, specious interpretation and the ever-anomalous Oenothera with its system of reciprocal interchanges. Darlington, at first as a junior worker with Newton, cleared away most of the confusion by 
the study of paired chromosomes at diakinesis in diploid and polyploid Hyacinthus and Tulipa so that he could write about tetraploids in 1929 "Only two chromosomes associate at any one point and frequent exchanges of partner take place amongst the four chromosomes; no part of a chromosome appears to be left unpaired". After careful examination of the chromosome pairs at diakinesis and metaphase in Prunus and Primula, in which chiasmata appear to be terminal at metaphase, he was able to interpret the difference in the number of chiasmata in the two stages by his hypothesis that interstitial chiasmata appear to move to the end of the chromosome and may cancel each other out by a process he called terminalisation.

During this early period Darlington was fully aware of the extreme difficulties of observation and interpretation particularly with small chromosomes, for he himself made a wrong interpretation of the nature of the metaphase configurations in the sweet cherry Prunus avium: a supposed trivalent made the somatically uncounted plant an aneuploid. This was fully corrected after he made a detailed analysis of chiasmata and the metaphase configuration resulting from them and, with the help of $\mathrm{M}$. B. Crane, had obtained the diploid somatic chromosome number. This awareness of the difficulties was also evident in his extreme caution in approaching the problem of the interpretation of chiasmata in relation to genetic crossing over. In his paper in 1929, "Meiosis in Polyploids", he states: "To return to the problem of the basis of genetical crossing over: we do not wish to re-open the question of the relation of chiasmata to crossing over in its widest aspects. The evidence on the genetical as well as on the cytological side is still altogether too scattered to enable one to put forward a working hypothesis with any possibility of its being generally applicable or useful". The caution may also have its origin in a deference to Newton who stated quite categorically in the John Innes report of 1924 that the configurations at diakinesis "do not support the theory of Janssens that they involve an actual interchange of material between the chromosomes". With the passing of another year, 1930, Darlington felt able to assemble all the evidence, cytological and genetical, in favour of a modified theory of Janssens and Belling so that he could write "all chiasmata result from crossing over between two chromatids of the partner chromosomes" (sic). The only new evidence forthcoming in the intervening year was further cytological observations of interlocking bivalents and novel genetical evidence of segregation in the ordered tetrad of Neurospora by Dodge.

There were naturally many points of controversy: a noted one was the lack of genetical crossing over in the male Drosophila melanogaster which Darlington later showed lacked true chiasmata in the autosomes and the paired chromosomes appeared to be held together at first metaphase by their centromeres; the sex chromosomes in the male which did appear to have a chiasma were explained on the basis of two close reciprocal chiasmata. Although the full explanation of chromosome pairing in the male Drosophila was to come much later with the electron microscopical studies which revealed the absence of synaptonemal complexes, the only inconsistency with Darlington's original explanation is that double reciprocal chiasmata are ruled out.

After a visit to the United States and Japan, Darlington studied the types of coiling of the chromosomes. This resulted in his torsion theory of pairing and crossing over by a process of breakage and an exchange reunion 
of chromatids favoured by the torsion between them which assisted pairing and when released by breakage caused the exchange and crossing over. This was as good and comprehensive a theory as could be devised on the existing knowledge and had the virtue of explaining a mechanism for genetical interference, but it was one of his theories which has not been supported by molecular studies and in that sense it was a good theory which has been disproved. Other important contributions were studies on the structure and function of the centromere, the origin of isochromosomes and a demonstration of configurations in Oenothera which showed that some crossing over occurred in this permanent hybrid. The concept of the structural hybrid first postulated in 1929 was developed together with a classification and explanation of the types of structural changes found in chromosomes, a study which later was a background for the work on spontaneous induced chromosome breaks and reunions which he did with L. F. La Cour and P. Koller. His theory of the fertility of polyploids, i.e., negative correlation with the diploids from which they arose, probably his first idea, has been a constant source of interpretation in plant cytogenetics. All his works and ideas and of others were published in "Recent Advances in Cytology" 1932, 2nd Edn. 1937, the great synthesiser and clarifyer which made geneticists, plant and animal breeders, cytologists and later medical practitioners aware of the importance of the study of chromosomes. The publication also had an important personal consequence for it made the Cytology Department of the John Innes Horticultural Institution under Darlington the centre of cytology so that a continuous stream of workers from most parts of the world came to work with C.D.D. These collaborators included K. Mather, Margaret Upcott, P. Koller, H. N. Barber, H. G. Callan, P. T. Thomas, E. K. Janaki-Ammal and later at Oxford C. G. Vosa, K. R. Lewis and A. Haque. Studies expanded into B chromosomes, misdivisions of the centromere and later, in collaboration with the protein chemist Astbury, an attempt to obtain X-ray diffraction patterns of Drosophila salivary gland chromosomes stretched parallel across a grid by Amicia Melland. It was extremely fortunate that L. F. La Cour came as a young man to join the staff as he promptly started to devise new and better fixations and staining schedules and to use his skill in the squash preparation instead of the tedious embedding and microtoming which could cause more artifacts through the inadequacies of slow fixation and the cutting of whole cells. La Cour's skill with stains culminated in the collaborative study of differential staining and localized "nucleic acid starvation".

All this produced an atmosphere of exciting activity in the laboratory which is worth recalling. The not unpleasant smell of clove oil, alcohol and xylol, the noise at first of the microtome and later the woodpecker-like tapping of the glass rods on slides for squash preparations and the clink of slides going through their alcoholic sequences were the constant sensory and musical background: each worker had enough room for a microscope, slide jars and a notebook. Darlington in his separate room with the door open, had his ancient brass microscope with a long tube originally bought second-hand by Bateson. The two simple home-made lensless cameras were constantly passing from one microscope to another to record the latest chromosome. There were frequent visits to the laboratory from the dark room of the presiding and charming genius of illustration and photography, the congenitally deaf $\mathrm{H}$. C. Osterstock, with whom everybody soon 
learned to converse in his own self-taught language. Darlington's room was lined with reprint boxes the spines of which were wittily illustrated with the most telling caricatures; one member of the early Drosophila school received H.J.M. and a crown, a sincere and not cynical comment: the several boxes of another showed a profile expanding from box to box with age which matched the ever increasing size and number of his publications. It was during this time that the second edition of Recent Advances was rewritten and part expanded into the "Evolution of Genetic Systems": a book of profound insight and inspiration and of lasting importance. With La Cour, the "Handling of Chromosomes" was more than a technical treatise of fixing and staining chromosomes for it contained as concise and sound advice on writing up the results that could be read with profit by any aspiring scientist. With Janaki-Ammal there was the chromosome atlas, the first comprehensive survey of chromosome numbers of cultivated plants and later a more comprehensive plant atlas with Ann Wylie. With Kenneth Mather the concise and comprehensive book "The Elements of Genetics" appeared in 1950 .

In the 1940s Darlington's interests became even broader and were divided between chromosomes, the cytoplasm, plasmagenes, viruses and also the genetics, history and behaviour of man and society. His thoughts on cytoplasmic determinants exercised a clarifying influence on the obscure problem of non-mendelian inheritance which had existed since Corren's work with Mirabilis and had been resuscitated by Sonneborn's work on Paramecium, Ephrussi on yeast and Rhoades on maize: nearer at home he stimulated a re-examination of such obscure phenomena as rogues in peas and tomatoes, bolting in potatoes and June yellows in strawberries and variegation in plants. The fine distinction between plasmagenes, viruses and infective particles was fully explored in several publications of which the most influential was "Heredity, Development and Infection", Nature, 1944.

Darlington's first work on the behaviour of chromosomes at meiosis was bombarded with criticism and controversy: his most recent interest summarised in "The Facts of Life" later rewritten as "Genetics of Man" 1964 and "The Evolution of Man and Society" has stimulated even more criticism, but this is twofold understandable; firstly, because of Darlington's provocative style and secondly because such a sociological subject as the history and behaviour of man is one in which emotion and spurious observation outnumber experiment and analysis. However, even here Darlington tried to be objective, for to assess the variability in sexual activity and fertility he turned for information to the pedigree stud books of cattle instead of Kinsey's treatise on the subject in man, for, as he wrote "bulls cannot boast". It was natural that he turned to the sociological aspects of population because he had a deep rooted love of history and the classics: this was evident from the wide ranging and apt quotations to be found in most of his books, those who knew him found this constantly in his conversation. On the political side he was fearlessly outspoken against Lysenko and the "War Against Science in the Soviet Union". His constant suspicion of the establishment and authority found expression in "The Dead Hand on Discovery" and "Genetics in the Universities". He was one of the first to deplore the unnatural schism between animals (Zoology) and plants (Botany), and used every opportunity to propagate the 
unification of biology through genetics. This had practical expression in the late 1940s when several new departments of genetics were founded in Universities which had either neglected or positively blocked the teaching of the subject. Some of the new chairs were occupied by his earlier collaborators. During his presidency of the Genetical Society, 1943-46, he enlarged the Year Book to include lists of journals of genetics and cytology and departments and institutes where relevant work was carried on-possibly a unique record of genetical activity at the time. At the end of the war he invited European geneticists to a meeting in London in November 1945. As Director of the John Innes from 1939 he was still able to give most of his time to research and at the same time to initiate and help to find a new site for the Institution, and when found to supervise the move from Merton, London to Bayfordbury, Hertford in 1949. In 1953, when he was elected to the Sherardian Chair of Botany at Oxford and Keeper of the Botanic Garden he was introduced to the realities and, to him, the frustrations of academic life. Teaching started, writing continued and his everlasting interest in chromosomes was crystallised into three chromosome conferences which he helped to organise. As a colleague and Director he was always helpful and encouraging; work should be published without too much delay for all science was preliminary, he never delayed in reading and understanding a manuscript submitted, however far removed from his main interests. He went to great trouble to improve the presentation, usually with diagrams and tables.

Darlington was firstly a man of ideas and hypotheses and secondly of observation and experiment which he has epitomized in his book "Darwin's place in History" by: "All of us like to be supported by earlier observations, but few of us like to be anticipated by earlier ideas". He was never interested in a career or power and he hated committees and had little patience for them; this was unfortunate because his full influence on research and teaching in biology could have been amplified manyfold in directions his genius alone could not reach. He was influenced not by those in authority but by working scientists particularly Weismann, Janssens, Belar, Muller, Haldane, W. G. F. Newton and Bateson. Important influences also came from visits abroad. In 1929 he visited Persia jointly with staff from Kew Gardens to collect Prunus and Tulipa spp. in order to fulfil his aim of "trying (in spite of the unsettled conditions in some regions) to form a collection of Prunus spp. from seed". A Rockefeller Fellowship in 1932 enabled him to work in the U.S.A. at Woods Hole, at Berkeley where he worked with John Belling on slides of Agapanthus and Kniphofia lent by Belling which contained excellent material for his later theories of the structure and function of the centromere. In Pasadena he met Beadle, Dobzhansky, Sturtevant and Morgan. Before returning to England he visited Japan where Kihara provided him with material of rye and oats, and from Kuwada preparations of Tradescantia showing most clearly the coiling of the chromosomes, which was the inspiration for his later work on coiling and the internal mechanics of the chromosomes. In 1934 he visited Leningrad where he gave a lecture on his theories of meiosis to the Academy of Sciences but he did not record any indications of the liquidation, to come, of genetics. Perhaps one of the meetings of most lasting consequences was a Gene Conference, or workshop as it would now be called, in Klampenborg organised by Timofeeff Ressovsky and Ephrussi 
in 1938 where he gave a paper on his ideas on chromosomes which lasted 6 hours to the group including Bernal, Astbury and Auger.

Darlington received many honours: FRS, 1941, Royal Medal, 1946, Tercentenary Lecture, 1960; Corr. Mem. Acc. Lincei., 1952, and of Roy. Soc. Copenhagen, 1952; D.Sc. Oxon. 1956, Trail Award Linn. Soc. 1951, Conway Memorial Lecture, 1948, Herbert Spencer Lecture, Oxford 1950, President Genetical Society 1943-46, President of the Rationalist Association, 1948, Fellow of Wye College, Fellow of Magdalen College Oxford, 1953-71.

Darlington often said that research unpublished is work not done and he published more than one hundred and fifty papers and many book reviews, but about 1935 he experienced difficulties in publishing his work. The papers were said to be unsuitable for the Journal of Experimental Biology and not genetical enough for the Journal of Genetics. Some of these difficulties could be avoided by publishing in foreign journals. This was impossible during and immediately after the war so he decided to publish his own journal, and hence Heredity was born in 1947 with the collaboration of $\mathbf{R}$. A. Fisher. The original cover surrounded by the names of past geneticists is another testimony of Darlington's historic sense. In 1969 Darlington, then the sole owner, offered the financially profitable Heredity to the Genetical Society on the conditions that it continued to be known as Heredity with the subtitle-"an International Journal of Genetics Founded by C. D. Darlington and R. A. Fisher in 1947"- that the editors should cover the several sections of genetics important for research papers and reviews, and a postscript "Since the transfer demands a consideration in return the present owner would be satisfied to receive copies of each part or supplement during his lifetime". This generous offer with its modest consideration was in keeping with his unpaid voluntary work at the start, and with his ever-present concern for scholarship and research. 